\title{
Inflammation and Reduced Parasympathetic Cardiac Modulation in Aortic-Valve Sclerosis
}

\author{
Juan C. Echeverría ${ }^{1}$, Nydia Ávila-Vanzzini ${ }^{2}{ }^{\circledR}$, Rashidi Springall ${ }^{3}$, José M. Torres-Arellano ${ }^{4}$, \\ Andrea Toledo ${ }^{3}$, Oscar Infante ${ }^{4}$, Rafael Bojalil ${ }^{5}$, Jorge Cossío ${ }^{2}$, Erika Fajardo ${ }^{2}$ and \\ Claudia Lerma ${ }^{4, * \text { (D) }}$ \\ 1 Department of Electrical Engineering, Universidad Autónoma Metropolitana, Unidad Iztapalapa, \\ Mexico City 09340, Mexico \\ 2 Department of Outpatients Clinic, Instituto Nacional de Cardiología Ignacio Chávez, \\ Mexico City 14080, Mexico \\ 3 Department of Immunology, Instituto Nacional de Cardiología Ignacio Chávez, Mexico City 14080, Mexico \\ 4 Department of Electromechanical Instrumentation, Instituto Nacional de Cardiología Ignacio Chávez, \\ Mexico City 14080, Mexico \\ 5 Department of Health Care, Universidad Autónoma Metropolitana, Unidad Xochimilco, \\ Mexico City 04960, Mexico \\ * Correspondence: dr.claudialerma@gmail.com; Tel.: +52-55-55732911 (ext. 26202)
}

Received: 30 August 2019; Accepted: 23 September 2019; Published: 26 September 2019

\begin{abstract}
Aortic-valve sclerosis increases cardiovascular mortality risk and precedes aortic-valve stenosis, but its mechanisms are not well understood. The purpose of this study was to compare the cardiac autonomic modulation and inflammation markers between subjects with aortic-valve normal leaflets and subjects with aortic-valve sclerosis. According to 2-D transthoracic echocardiograms, 61 middle-aged volunteers without chronic or acute illnesses were classified in two groups: with no aortic-valve sclerosis (NAVS, $\mathrm{N}=16$ ) and with aortic-valve sclerosis (AVS, $\mathrm{N}=45$ ). An electrocardiogram at the supine position and active standing was collected to estimate heart rate variability $(\mathrm{HRV})$ indices. A blood sample was obtained to quantify markers of inflammation. Compared to NAVS, AVS subjects showed higher levels of IL-6 (1619 \pm 650 vs. $1169 \pm 676 \mathrm{pg} / \mathrm{mL}$, $p=0.044)$ as well as TNF $\alpha(370.8 \pm 182.0$ vs. $247.3 \pm 188.2 \mathrm{pg} / \mathrm{mL}, p=0.032)$, and larger low-frequency (LF) to high-frequency $(\mathrm{HF})$ ratio during supine position $(\mathrm{Ln}(\mathrm{LF} / \mathrm{HF})=0.85 \pm 0.85$ vs. $0.11 \pm 0.69, p=0.003)$. Multiple logistic regression analysis showed that AVS was independently associated with $\mathrm{LF} / \mathrm{HF}, \mathrm{TNF} \alpha$ and left ventricle mass index $(p<0.05)$. In conclusion, a significant reduction of the parasympathetic-driven cardiac modulation and low-grade inflammation occurs in aortic-valve sclerosis.
\end{abstract}

Keywords: aortic valve disease; cardiac autonomic modulation; heart rate variability; inflammation

\section{Introduction}

The main factors involved in the initiation of aortic-valve sclerosis are both endothelial dysfunction with inflammation and lipid infiltration [1,2]. Progression from aortic-valve sclerosis to calcific aortic-valve stenosis is slow and occurs in about $10 \%-15 \%$ of patients [3,4]. Aortic-valve sclerosis entails focal or diffuse leaflets thickening but no functional hemodynamic effects are identified [5]. However, aortic-valve sclerosis has been associated with an increased cardiovascular risk [6].

Among different mechanism affected or modified by aortic-valve disease, the autonomic regulation, as assessed by heart rate variability (HRV), has been mainly examined in patients manifesting severe aortic-valve stenosis [7-11]. HRV refers to the interval fluctuations between consecutive heart 
beats $[12,13]$. These fluctuations in the heart rate are modulated by many mechanisms including the interaction with the respiratory cycle (respiratory sinus arrhythmia) [14], the baroreflex mechanism [15], and the autonomic nervous system modulation of the sinus node through norepinephrine released from sympathetic nerves and acetylcholine released from the parasympathetic nerves [16]. Such studies of severe aortic-valve stenosis evaluated HRV with statistical indices (such as the standard deviation of all heart-beats intervals) and provided evidence of an overall HRV reduction that indicates an impaired heart's autonomic control, presumably involving a vagal withdrawal and an increased sympathetic activity [7-11]. Other HRV indices based on power spectrum analysis estimate the contribution of the sympathetic and parasympathetic modulation on the HRV fluctuations at different frequencies $[12,16]$.

Given that aortic-valve sclerosis is accompanied by an active inflammatory response, and to obtain a deeper insight into cardiac autonomic modulation, in this exploratory study we compared HRV indices and inflammation markers between subjects with aortic-valve sclerosis and subjects with normal valve leaflets. To our knowledge, this is the first study to assess the autonomic regulation of subjects with aortic-valve sclerosis.

\section{Materials and Methods}

\subsection{Subjects and Study Protocol}

We designed a cross-sectional, descriptive and analytical study. Sixty-one volunteers who lived in urban areas of Mexico participated in this study. Their age ranged from 32 to 63 years old (mean \pm standard deviation $=47 \pm 7$ years) having a body mass index $=29.3 \pm 4.7 \mathrm{Kg} / \mathrm{m}^{2}, 30$ of them $(49 \%)$ were female. None of these subjects were known to have diabetes, oncological, cardiovascular, renal, hepatic or autoimmune diseases. They did not present any infectious illness or were vaccinated within three months before their participation. Volunteers were not receiving statin or beta-blockers or any other medication. Subjects were requested to fast for at least eight hours before the study. After providing their written informed consent (the study complied with the 1975 Declaration of Helsinki and it was approved by the Ethics and Research Committee with number 16-993), their oscillometric blood pressure, anthropometric measures, and standard resting electrocardiogram (ECG) of 12 leads were obtained. This assessment was followed by a further ECG recording using a chest belt (BioHarness 3.0, Zephyr) to collect high frequency data (1000 samples per second) while subjects laid in supine position for $10 \mathrm{~min}$ and for another $10 \mathrm{~min}$ at and active standing position. Then, a blood sample was taken and, finally, a conventional 2D transthoracic echocardiographic assessment was performed by a single expert who was blinded to the HRV and serum analyses.

\subsection{Echocardiographic Assessment and Study Groups}

Following current guidelines [17], conventional transthoracic echocardiograms (iE33, Philips Healthcare) were performed. A pulsed-wave Doppler recording was obtained to assess the maximum aortic valve transvalvular velocity in meters per second $(\mathrm{m} / \mathrm{s})$ and the mean pressure gradient $(\mathrm{mmHg})$. Aortic-valve sclerosis was identified by calcified focal areas of increased echogenicity and thickened aortic-valve leaflets with no motion restriction or obstruction of the left ventricular outflow tract and antegrade flow [18,19]. According to Yousry M. et al [20], subjects were classified in two groups: those who had normal aortic valve (i.e. no aortic-valve sclerosis, NAVS N =16) and those who had any ultrasound indication of aortic-valve sclerosis (AVS, $N=45$ ). All subjects had a three-leaflet aortic valve. Left ventricular ejection fraction (\%), left ventricle mass (g), left ventricular mass indexed to body surface area $\left(\mathrm{g} / \mathrm{m}^{2}\right)$ and relative wall thickness were also obtained [17].

\subsection{Beat Identification and HRV Analysis}

About 5 min of the ECG recordings in each position (supine position and active standing) were selected to obtain 300 heart-period intervals or HRV time series. The ECG QRS complexes were 
identified by a second derivative algorithm, followed by manual inspections to remove artifacts and ectopic beats. None of the HRV time series required more than $1 \%$ of beats replacement.

HRV indices were assessed from the 300 consecutive RR intervals obtained at the supine position and active standing. The following HRV time-domain indices were calculated for each time series: mean NN (average value of all RR intervals), SDNN (standard deviation of all RR intervals) and pNN20 (percentage of successive RR intervals with differences greater to $20 \mathrm{~ms}$ ). For estimating frequency domain HRV indices, each time series was resampled with a linear interpolation method at three samples per second and the power spectrum density was estimated by Welch's periodogram method. The mean spectral power was obtained for the low frequency (LF) band $(0.04$ to $0.15 \mathrm{~Hz})$ and the high frequency (HF) band ( 0.15 to $0.4 \mathrm{~Hz}$ ). The LF and HF indices were transformed to normalized units (n.u.) [12]. Whereas LF reflects both sympathetic and parasympathetic activities, HF is regarded as a reliable parameter of the vagal cardiac control [9,12]. The fractal indices $\alpha_{1}$ and $\alpha_{1 \text { sign }}$ were calculated for each original HRV time series with detrended fluctuation analysis within the short-range of scales (4 to 11 RR intervals) [21,22]. These indices indicate the irregularity and directionality of time series, which are influenced by the cardiac-autonomic interplay [22]. For all indices, the difference $(\Delta)$ between values at the supine position minus values at active standing was also estimated. The HRV indices estimation was performed with ad-hoc computer programs developed in Matlab (MathWorks, Inc.).

\subsection{Serum Analysis}

A $10 \mathrm{ml}$ blood sample was taken from each participant. Samples were centrifuged at $600 \mathrm{rpm}$ for $15 \mathrm{~min}$ at $4{ }^{\circ} \mathrm{C}$ and stored in aliquots at $-76^{\circ} \mathrm{C}$. Serum concentrations of Matrix Metalloproteinase-3 (MMP3), Matrix Metallopeptidase-9 (MMP-9), Tissue Inhibitor of Metalloproteinase-1 (TIMP-1), Interleukin 6 (IL-6), Interleukin 12 (IL-12), Interleukin 10 (IL-10), Interferon Gamma (IFN- $\gamma$ ), Tumor Necrosis Factor alpha (TNF- $\alpha$ ), Tumor Growth Factor-beta (TGF- $\beta$ ), Leukotriene B4 (LTB4), Lipoxin A4 (LXA4), Endothelin 1 (ET-1), Prostaglandin E2 (PGE-2) and Resolving D1 (RvD1) were measured by enzyme-linked immunosorbent assays (R\&D Systems). The serum levels of C-reactive protein were determined by nephelometry (Beckman Coulter).

\subsection{Statistical Analysis}

Nominal variables are reported by absolute values (percentage) and were compared between groups by Chi-squared test. For ordinal variables, a Kolmorogov-Smirnov test was applied to assess if a normal distribution could be assumed $(p>0.05)$. In such a case, the results, considered by mean \pm standard deviation, were compared between groups (NAVS vs. AVS) by a Student $\mathrm{t}$ test. If normal distribution could not be assumed, the variables, reported as median (percentile 25-percentile 75), were compared between groups by Mann-Whitney U test. A logistic regression analysis was performed to evaluate the association between the existence of aortic-valve sclerosis (as dependent variable) and some selected variables representative of the autonomic modulation (i.e., $\mathrm{LF} / \mathrm{HF}$ ), inflammation (i.e., $\mathrm{TNF} \alpha$ ) and ventricular remodeling (i.e., left ventricular mass index).The statistical analysis was performed by SPSS version 21.0 (IBM Corp., Armonk, N.Y.USA).

\section{Results}

All anthropometric and clinical variables as well as laboratory results were similar between groups (Table 1). All variables were within normal range, except for the body mass index and C-reactive protein values. 
Table 1. Anthropometric and clinical characteristics. Data are shown as absolute value (percentage), mean \pm standard deviation or median (percentile 25-percentile 75).

\begin{tabular}{lccc}
\hline \multicolumn{1}{c}{ Variable } & NAVS $\mathbf{( N ~ = ~ 1 6 )}$ & AVS (N = 45) & $p$ Value \\
\hline Age (years) & $45 \pm 6$ & $48 \pm 8$ & 0.106 \\
Female sex & $9(56 \%)$ & $21(47 \%)$ & 0.357 \\
Body mass index $\left(\mathrm{Kg} / \mathrm{m}^{2}\right)$ & $28.6 \pm 3.6$ & $29.5 \pm 5$ & 0.409 \\
Systolic blood pressure $(\mathrm{mmHg})$ & $112(105-119)$ & $120(110-130)$ & 0.157 \\
Diastolic blood pressure $(\mathrm{mmHg})$ & $80(76-80)$ & $80(70-85)$ & 0.937 \\
Heart rate (beats per minute) & $62.4 \pm 7.0$ & $61.4 \pm 8.9$ & 0.346 \\
Serum glucose $(\mathrm{mg} / \mathrm{dL})$ & $87.5 \pm 13.5$ & $90.2 \pm 9.9$ & 0.474 \\
Albumin $(\mathrm{mg} / \mathrm{dL})$ & $4.3 \pm 0.2$ & $4.4 \pm 0.3$ & 0.337 \\
Total cholesterol $(\mathrm{mg} / \mathrm{dL})$ & $198 \pm 36$ & $195.6 \pm 41.4$ & 0.814 \\
High density lipids $(\mathrm{mg} / \mathrm{dL})$ & $39.2 \pm 10.4$ & $43.4 \pm 9.3$ & 0.170 \\
Low density lipids $(\mathrm{mg} / \mathrm{dL})$ & $131 \pm 34$ & $123 \pm 36$ & 0.474 \\
Triglycerides $(\mathrm{mg} / \mathrm{dL})$ & $150(128-168)$ & $154(100-193)$ & 0.844 \\
Atherogenic index & $3.5 \pm 1.2$ & $2.9 \pm 0.9$ & 0.080 \\
C-reactive protein $(\mathrm{mg} / \mathrm{dL})$ & $2.6(1.4-3.6)$ & $2.3(1.2-4.8)$ & 0.793 \\
C-reactive protein $>1$ & $14(88 \%)$ & $38(84 \%)$ & 0.673 \\
Hemoglobin $(\mathrm{mg} / \mathrm{dL})$ & $14.8 \pm 1.9$ & $15.0 \pm 1.9$ & 0.971 \\
Hematocrit $(\%)$ & $44.8 \pm 4.9$ & $44.7 \pm 4.8$ & 0.197 \\
Leukocytes count $(\mathrm{per} \mu \mathrm{cL})$ & $7.5 \pm 2.3$ & $6.7 \pm 1.6$ & 0.106 \\
\hline
\end{tabular}

NAVS = no aortic-valve sclerosis; AVS = aortic-valve sclerosis

AVS subjects had significantly larger left ventricular mass index and relative wall thickness compared to NAVS subjects (Table 2), while all other echocardiographic indices were similar between groups.

Table 2. Indices from echocardiogram and electrocardiogram.

\begin{tabular}{lccc}
\hline \multicolumn{1}{c}{ Variable } & NAVS $\mathbf{( N = 1 6 )}$ & AVS $(\mathbf{N}=\mathbf{4 5})$ & $p$ Value \\
\hline QRS width $(\mathrm{ms})$ & $93.9 \pm 8.3$ & $95.1 \pm 10.5$ & 0.644 \\
PR interval $(\mathrm{ms})$ & $150.6 \pm 27.7$ & $157.4 \pm 18.5$ & 0.376 \\
Left ventricular ejection fraction $(\%)$ & $62.3 \pm 6.1$ & $60.4 \pm 5.9$ & 0.278 \\
Aortic-valve maximum flow velocity $(\mathrm{m} / \mathrm{s})$ & $1.2 \pm 0.3$ & $1.3 \pm 0.2$ & 0.446 \\
Aortic-valve mean gradient $(\mathrm{mmHg})$ & $3(2-3)$ & $3(2-4)$ & 0.288 \\
Left ventricle mass $(\mathrm{g})$ & $103 \pm 27$ & $127 \pm 40$ & 0.010 \\
Left ventricle mass index $\left(\mathrm{g} / \mathrm{m}^{2}\right)$ & $55 \pm 12$ & $68 \pm 17$ & 0.001 \\
Relative Wall Thickness & $0.37 \pm 0.06$ & $0.41 \pm 0.09$ & 0.030 \\
Relative Wall Thickness $>0.42$ & $3(19 \%)$ & $17(38 \%)$ & 0.222 \\
\hline
\end{tabular}

Serum markers of the inflammation process are shown in Table 3. In comparison with NAVS subjects, the AVS group presented significantly higher serum levels of IL-6 and TNF $\alpha$. All other markers were similar between groups. 
Table 3. Markers of the inflammation process.

\begin{tabular}{lccc}
\hline \multicolumn{1}{c}{ Variable } & NAVS $(\mathbf{N}=\mathbf{1 6})$ & AVS $(\mathbf{N}=\mathbf{4 5})$ & $p$ Value \\
\hline IL-6 $(\mathrm{pg} / \mathrm{mL})$ & $1161 \pm 767$ & $1619 \pm 645$ & 0.044 \\
IL-12 $(\mathrm{pg} / \mathrm{mL})$ & $150.7(91.8-536.6)$ & $157.5(91.8-293.3)$ & 0.547 \\
TNF $\alpha(\mathrm{pg} / \mathrm{mL})$ & $247.3 \pm 188.2$ & $370.8 \pm 182.0$ & 0.032 \\
IFN- $\gamma(\mathrm{pg} / \mathrm{mL})$ & $140.5 \pm 130.5$ & $181.6 \pm 151.7$ & 0.308 \\
ET1 $(\mathrm{pg} / \mathrm{mL})$ & $51.64 \pm 13.34$ & $51.61 \pm 8.64$ & 0.993 \\
LTB4 $(\mathrm{pg} / \mathrm{mL})$ & $1362 \pm 309$ & $1326 \pm 339$ & 0.705 \\
PGE2 $(\mathrm{pg} / \mathrm{mL})$ & $594.4 \pm 287.9$ & $635.9 \pm 267.5$ & 0.618 \\
IL-10 $(\mathrm{pg} / \mathrm{mL})$ & $32.3 \pm 12.6$ & $30.9 \pm 11.1$ & 0.700 \\
TGF- $\beta(\mathrm{pg} / \mathrm{mL})$ & $693.1(589.7-899.8)$ & $644.4(547.2-753.8)$ & 0.298 \\
LXA4 $(\mathrm{ng} / \mathrm{mL})$ & $7.08(1.90-21.29)$ & $2.94(0.18-16.63)$ & 0.226 \\
RvD1 $(\mathrm{pg} / \mathrm{mL})$ & $75.24 \pm 6.04$ & $75.78 \pm 7.70$ & 0.775 \\
\hline
\end{tabular}

At the supine position, AVS subjects had significantly smaller HF as well as larger LF, LF/HF, $\alpha_{1}$, and $\alpha_{1 \text { sign }}$ indices than NAVS subjects, while mean NN and time domain indexes (SDNN and pNN20) were similar between groups (Table 4). During the orthostatic position all HRV indexes were similar between groups. Compared with the NAVS group, the AVS group had significantly smaller change between the supine position and active standing (i.e., $\Delta$ ) in SDNN, LF, HF, and $\alpha_{1 \text { sign }}$. Multiple logistic regression analysis with representative indices of autonomic modulation (LF/HF), inflammatory markers (TNF $\alpha$ and IL6) and ventricular remodeling (LV mass index and RWT) found that larger values of LF/HF (O.R. $=2.720,95 \%$ CI: 1.117 to $6.620, p=0.027)$, TNF $\alpha$ (O.R. $=1.005,95 \%$ CI: 1.000 to $1.009, p=0.041)$ and LV mass index (O.R. $=1.075,95 \%$ CI: 1.005 to $1.151, p=0.035)$ were all significant independent predictors of the occurrence of aortic-valve sclerosis.

Table 4. Heart rate variability indices.

\begin{tabular}{|c|c|c|c|}
\hline Variable & NAVS $(N=16)$ & AVS $(N=45)$ & $p$ Value \\
\hline \multicolumn{4}{|l|}{ Supine position } \\
\hline Mean NN (s) & $0.997 \pm 0.120$ & $0.995 \pm 0.143$ & 0.657 \\
\hline SDNN (s) & $0.050 \pm 0.015$ & $0.062 \pm 0.030$ & 0.156 \\
\hline pNN20 (\%) & $59.7 \pm 15.9$ & 53. $9 \pm 21.2$ & 0.326 \\
\hline LF (n.u.) & $52.9 \pm 15.6$ & $67.9 \pm 15.8$ & 0.002 \\
\hline HF (n.u.) & $47.2 \pm 15.7$ & $32.3 \pm 15.9$ & 0.002 \\
\hline $\mathrm{LF} / \mathrm{HF}$ & $1.14(0.782-2.12)$ & $2.42(1.53-3.29)$ & 0.001 \\
\hline $\mathrm{Ln}(\mathrm{LF} / \mathrm{HF})$ & $0.11 \pm 0.69$ & $0.85 \pm 0.85$ & 0.003 \\
\hline$\alpha_{1}$ & $0.988 \pm 0.238$ & $1.165 \pm 0.276$ & 0.026 \\
\hline$\alpha_{1 \text { sign }}$ & $0.154 \pm 0.146$ & $0.276 \pm 0.201$ & 0.030 \\
\hline \multicolumn{4}{|l|}{ Orthostatic position } \\
\hline Mean NN (s) & $0.806 \pm 0.094$ & $0.846 \pm 0.097$ & 0.097 \\
\hline SDNN (s) & $0.050 \pm 0.013$ & $0.045 \pm 0.014$ & 0.237 \\
\hline pNN20 (\%) & $40.6 \pm 18.0$ & $32.5 \pm 17.6$ & 0.121 \\
\hline LF (n.u.) & $82.4 \pm 10.9$ & $84.1 \pm 9.1$ & 0.537 \\
\hline HF (n.u.) & $17.7 \pm 10.9$ & $16 \pm 9.2$ & 0.547 \\
\hline $\mathrm{LF} / \mathrm{HF}$ & $5.84(3.67-8.61)$ & $6.36(3.48-8.68)$ & 0.670 \\
\hline $\operatorname{Ln}(\mathrm{LF} / \mathrm{HF})$ & $1.70 \pm 0.74$ & $1.82 \pm 0.70$ & 0.570 \\
\hline$\alpha_{1}$ & $1.41 \pm 0.21$ & $1.45 \pm 0.20$ & 0.572 \\
\hline$\alpha_{1 \text { sign }}$ & $0.46 \pm 0.13$ & $0.47 \pm 0.15$ & 0.948 \\
\hline \multicolumn{4}{|c|}{ Changes between manoeuvres } \\
\hline$\Delta$ Mean NN (s) & $0.170 \pm 0.080$ & $0.150 \pm 0.090$ & 0.327 \\
\hline$\triangle \mathrm{SDNN}(\mathrm{s})$ & $0.001 \pm 0.015$ & $0.017 \pm 0.029$ & 0.006 \\
\hline$\Delta$ pNN20 (\%) & $19.1 \pm 12.3$ & $21.5 \pm 17.2$ & 0.563 \\
\hline$\Delta \mathrm{LF}$ (n.u.) & $-29.5 \pm 16.8$ & $-16.2 \pm 15.1$ & 0.010 \\
\hline$\Delta \mathrm{HF}$ (n.u.) & $29.5 \pm 16.8$ & $16.4 \pm 15.2$ & 0.011 \\
\hline$\Delta \mathrm{LF} / \mathrm{HF}$ & $-5.53(-6.99--2.07)$ & $-4.54(-6.18--1.17)$ & 0.425 \\
\hline$\Delta \alpha_{1}$ & $-0.430 \pm 0.250$ & $-0.280 \pm 0.290$ & 0.065 \\
\hline$\Delta \alpha_{1 \text { sign }}$ & $-0.310 \pm 0.170$ & $-0.190 \pm 0.200$ & 0.032 \\
\hline
\end{tabular}




\section{Discussion}

Our main finding is the existence of significant HRV differences in subjects having aortic-valve sclerosis, mainly identified by a reduction of the parasympathetic-driven variability (or increased adrenergic-like response) to the cardiac autonomic modulation. This exploration seems to be the first study documenting that functional subclinical lesions of the aortic valve are accompanied by HRV changes.

Subjects with aortic-valve sclerosis also showed significant differences in the left ventricular mass index and relative wall thickness in comparison with normal aortic valve subjects but none of the participants reached a ventricular mass index large enough to fulfill the accepted criteria for hypertrophy [17]. In studies involving severe clinical conditions, such as aortic-valve stenosis and hypertensive heart disease, cardiac hypertrophy has been associated with diminished indices of HRV [23]. Our AVS group, who had by contrast a normal ventricular structure, also showed cardiac autonomic HRV changes (i.e., increased LF, LF/HF, and $\alpha_{1 \text { sign }}$ and reduced HF at the supine position). The active standing maneuver in AVS subjects introduced a diminished adjustment (i.e., $\Delta$ ), or constricted autonomic response, in most of these HRV indices as well. This maneuver essentially involves a vagal withdrawal and a sympathetic activation in response to the redistribution of blood from central- to lower-body vascular beds [24]. Overall, these standing adjustments and supine differences suggest a reduction of the parasympathetic-driven variability in aortic-valve sclerosis, which is revealed by the increased LF spectral power, reduced spectral HF power, smother variability $\left(\alpha_{1}\right)$ and less anti-correlated $\left(\alpha_{1 \text { sign }}\right)$ HRV behavior [25]. Importantly, this reduction was concomitant with no differences in the mean NN parameter in the supine position (Table 1)—thereby such a reduction cannot be simply attributed to baseline differences in the heart rate [26].

Several studies have associated a diminished HRV with increased mortality of cardiovascular diseases [27]. Particularly, a decreased vagal function was related to both modifiable and non-modifiable cardiovascular risk factors and it was also associated with coronary artery occlusion and plaque rupture [27].

Aortic-valve sclerosis is related to coronary artery disease and inflammation [1] and it is recognized as a marker of cardiovascular risk $[6,8]$. Aortic-valve sclerosis thus appears to have a pathogenic link with coronary atherosclerosis, but it also involves other mechanisms resulting in an active inflammatory response that increases the susceptibility of patients [6,18].

Here, we provide further evidence showing that early sclerotic aortic-valve lesions are accompanied by HRV changes that are probably related to such inflammatory response. Most subjects of both groups studied had similar but abnormal higher plasma levels of C-reactive protein and overweight body mass index (Table 1). However, the aortic-valve sclerosis group showed significantly higher plasma levels of IL- 6 and TNF $\alpha$ that are in line with an active inflammatory response. These cytokines cause both paracrine and endocrine effects that mediate local and systemic responses [28,29]). According to a recent review [30], the expression of pro-inflammatory cytokines, such as TGF- $\beta$, TNF $\alpha$, IL-1 $\beta$, and IL-6, is consistently identified in aortic-valve sclerosis. These cytokines seem to be produced by leaflets' activated fibroblasts, whose differentiation, proliferation, and matrix remodeling participate in the endothelial damage of aortic valve leading to the valve thickening [30]. IL-6 is also known to be involved in the endothelial dysfunction of other cardiovascular diseases by interfering with endothelial nitric oxide synthase expression [31] and, in conjunction with C-reactive protein, is regarded as an indicator of chronic or systemic low-grade inflammation [18]. Other authors have associated IL-6 with a reduced HRV as they documented that its levels show an indirect relationship with the LF and HF power bands once controlling for age, gender, ethnicity, smoking status, blood pressure, and body mass index [32]. Moreover, the increased HF power of HRV is inversely related to lower TNF $\alpha$ levels in accordance with the identification that vagal activity downregulates the production of TNF $\alpha$ in endotoxin-stimulated blood [33]. The expression of TNF $\alpha$ has been associated to the production of reactive oxygen species implicated as well in the endothelial dysfunction of other pathophysiological conditions [34]. 


\section{Limitations}

The sample in this study is small and asymmetrical, having fewer subjects in the NAVS groups owing to the strict compliance with the diagnostic criteria for aortic-valve sclerosis of the current guidelines [17,20]. Additional research with a larger number of participants is warranted to confirm our present findings. Future studies quantifying the degree of aortic-valve sclerosis are needed to determine associations between the degree of sclerosis and HRV indices. Other studies are also required to assess the involvement of factors such as body mass composition, physical activity, and the concomitant manifestation of various heart-valve lesions.

\section{Conclusions}

In conclusion, early aortic-valve subclinical lesions are accompanied by significant HRV differences. These differences suggest a reduction of the parasympathetic-driven variability (or increased adrenergic-like response) to the cardiac autonomic modulation and may result from a systemic low-grade inflammation. Importantly, $\mathrm{LF} / \mathrm{HF}, \mathrm{TNF} \alpha$, and $\mathrm{LV}$ mass index were independently associated with aortic-valve sclerosis.

Author Contributions: Conceptualization, J.C.E., N.Á.-V., R.S., O.I., R.B., J.C. and C.L.; methodology, J.C.E., N.Á.-V., R.S., O.I. and C.L.; software, J.C.E. and C.L.; validation, J.C.E., C.L., N.Á.-V. and R.S.; formal analysis, J.C.E., C.L., J.M.T.-A.; investigation, J.C.E., C.L., N.Á.-V., R.S., and R.B.; resources, J.C.E., R.S., R.B., J.C. and C.L.; data curation, J.C.E., R.S., J.M.T.A, A.T., E.F. and C.L.; writing-original draft preparation, J.C.E. and C.L.; writing - review and editing, N.Á.-V., R.S., J.M.T.A, A.T., O.I., R.B., J.C. and E.F.; visualization, C.L.; supervision, C.L., R.B., J.C.E. and N.Á.-V.; project administration, C.L., R.S. and N.Á.-V.; funding acquisition, J.C.E. and R.S.

Funding: This research received no external funding.

Acknowledgments: The authors wish to acknowledge the skillful assistance of Martha Ríos-Castro in collecting data from participants. This research received no grant from any funding agency in the public, commercial or not-for-profit sectors.

Conflicts of Interest: The Authors declare that there is no conflict of interest.

\section{References}

1. Chandra, H.R.; Goldstein, J.A.; Choudhary, N.; O'Neill, C.S.; George, P.B.; Gangasani, S.R.; Cronin, L.; Marcovitz, P.A.; Hauser, A.M.; O'Neill, W.W. Adverse outcome in aortic sclerosis is associated with coronary artery disease and inflammation. J. Am. Coll. Cardiol. 2004, 43, 169-175. [CrossRef] [PubMed]

2. Otto, C.M.; Prendergast, B. Aortic-Valve Stenosis-From Patients at Risk to Severe Valve Obstruction. N. Engl. J. Med. 2014, 371, 744-756. [CrossRef] [PubMed]

3. Novaro, G.M.; Katz, R.; Aviles, R.J; Gottdiener, J.S.; Cushman, M.; Psaty, B.M.; Otto, C.M.; Griffin, B.P. Clinical factors, but not C-reactive protein, predict progression of calcific aortic-valve disease: The Cardiovascular Health Study. J. Am. Coll. Cardiol. 2007, 50, 1992-1998. [CrossRef] [PubMed]

4. Owens, D.S.; Katz, R.; Takasu, J.; Kronmal, R.; Budoff, M.J.; O’Brien, K.D. Incidence and progression of aortic valve calcium in the Multi-ethnic Study of Atherosclerosis (MESA). Am. J. Cardiol. 2010, 105, 701-708. [CrossRef] [PubMed]

5. Gharacholou, S.M.; Karon, B.L.; Shub, C.; Pellikka, P.A. Aortic valve sclerosis and clinical outcomes: Moving toward a definition. Am. J. Med. 2011, 124, 103-110. [CrossRef] [PubMed]

6. Di Minno, M.N.D.; Di Minno, A.; Ambrosino, P.; Songia, P.; Pepi, M.; Tremoli, E.; Poggio, P. Cardiovascular morbidity and mortality in patients with aortic valve sclerosis: A systematic review and meta-analysis. Int. J. Cardiol. 2018, 260, 138-144. [CrossRef] [PubMed]

7. Airaksinen, K.E.; Ikaheimo, M.J.; Koistinen, M.J.; Takkunen, J.T. Impaired vagal heart rate control in aortic valve stenosis. Eur. Heart J. 1988, 9, 1126-1130. [CrossRef] [PubMed]

8. Arslan, U.; Ozdemir, M.; Kocaman, S.A.; Balcioglu, S.; Cemri, M.; Cengel, A. Heart rate variability and heart rate turbulence in mild-to-moderate aortic stenosis. Europace 2008, 10, 1434-1441. [CrossRef] [PubMed]

9. Jung, J.; Heisel, A.; Butz, B.; Fries, R.; Schieffer, H.; Tscholl, D.; Schäfers, H.J. Factors influencing heart rate variability in patients with severe aortic valve disease. Clin. Cardiol. 1997, 20, 341-344. [CrossRef] 
10. Kokosinska, D.; Gieraltowski, J.J.; Zebrowski, J.J.; Orlowska-Baranowska, E.; Baranowski, R. Heart rate variability, multifractal multiscale patterns and their assessment criteria. Physiol. Meas. 2018, 39, 114010. [CrossRef] [PubMed]

11. Zuern, C.S.; Eick, C.; Rizas, K.D.; Stoleriu, C.; Barthel, P.; Scherer, C.; Müller, K.A.; Gawaz, M.; Bauer, A. Severe autonomic failure in moderate to severe aortic stenosis: Prevalence and association with hemodynamics and biomarkers. Clin. Res. Cardiol. 2012, 101, 565-572. [CrossRef] [PubMed]

12. Task Force of the European Society of Cardiology and the North American Society of Pacing and Electrophysiology. Heart rate variability: Standards of measurement, physiological interpretation and clinical use. Circulation 1996, 93, 1043-1065. [CrossRef]

13. Sassi, R.; Cerutti, S.; Lombardi, F.; Malik, M.; Huikuri, H.V.; Peng, C.K.; Schmidt, G.; Yamamoto, Y. Advances in heart rate variability signal analysis: Joint position statement by the e-Cardiology ESC Working Group and the European Heart Rhythm Association co-endorsed by the Asia Pacific Heart Rhythm Society. Europace 2015, 17, 1341-1353. [CrossRef] [PubMed]

14. Elstad, M.; O'Callaghan, E.L.; Smith, A.J.; Ben-Tal, A.; Ramchandra, R. Cardiorespiratory interactions in humans and animals: Rhythms for life. Am. J. Physiol. Heart Circ. Physiol. 2018, 315, H6-H17. [CrossRef] [PubMed]

15. Estanol, B.; Porras-Betancourt, M.; Sánchez-Torres, R.; Martínez-Memije, R.; Infante, O.; Senties-Madrid, H. Neural control of the peripheral circulation and blood pressure. Arch. Cardiol. Mex. 2009, 79, 109-116. [PubMed]

16. Shaffer, F.; McCraty, R.; Zerr, C.L. A healthy heart is not a metronome: An integrative review of the heart's anatomy and heart rate variability. Front. Physiol. 2014, 5, 1040. [CrossRef]

17. Lang, R.M.; Badano, L.P.; Mor-Avi, V.; Afilalo, J.; Armstrong, A.; Ernande, L.; Flachskampf, F.A.; Foster, E.; Goldstein, S.A.; Kuznetsova, T.; et al. Recommendations for cardiac chamber quantification by echocardiography in adults: An update from the American Society of Echocardiography and the European Association of Cardiovascular Imaging. J. Am. Soc. Echocardiogr. 2015, 28, 1-39. [CrossRef] [PubMed]

18. Nightingale, A.K.; Horowitz, J.D. Aortic sclerosis: Not an innocent murmur but a marker of increased cardiovascular risk. Heart 2005, 91, 1389-1393. [CrossRef]

19. Otto, C.M.; Lind, B.K.; Kitzman, D.W.; Gersh, B.J.; Siscovick, D.S. Association of aortic-valve sclerosis with cardiovascular mortality and morbidity in the elderly. N. Engl. J. Med. 1999, 341, 142-147. [CrossRef]

20. Yousry, M.; Rickenlund, A.; Petrini, J.; Nenner, J.; Liska, J.; Eriksson, P.; Franco-Cereceda, A.; Eriksson, M.J.; Caidahl, K. Aortic valve type and calcification as assessed by transthoracic and transoesophageal echocardiography. Clin. Physiol. Funct. Imaging 2015, 35, 306-313. [CrossRef]

21. Peng, C.K.; Havlin, S.; Stanley, H.E.; Goldberger, A.L. Quantification of scaling exponents and crossover phenomena in nonstationary heartbeat time series. Chaos 1995, 5, 82-87. [CrossRef] [PubMed]

22. Ashkenazy, Y.; Ivanov, P.C.; Havlin, S.; Peng, C.K.; Goldberger, A.L.; Stanley, H.E. Magnitude and sign correlations in heartbeat fluctuations. Phys. Rev. Lett. 2001, 86, 1900-1903. [CrossRef] [PubMed]

23. Alter, P.; Grimm, W.; Vollrath, A.; Czerny, F.; Maisch, B. Heart rate variability in patients with cardiac hypertrophy-Relation to left ventricular mass and etiology. Am. Heart J. 2006, 151, 829-836. [CrossRef] [PubMed]

24. Cooke, W.H.; Hoag, J.B.; Crossman, A.A.; Kuusela, T.A.; Tahvanainen, K.U.; Eckberg, D.L. Human responses to upright tilt: A window on central autonomic integration. J. Physiol. 1999, 517, 617-628. [CrossRef] [PubMed]

25. Lerma, C.; Echeverria, J.C.; Infante, O.; Pérez-Grovas, H.; González-Gómez, H. Sign and magnitude scaling properties of heart rate variability in patients with end-stage renal failure: Are these properties useful to identify pathophysiological adaptations? Chaos 2017, 27, 093906. [CrossRef] [PubMed]

26. Sacha, J.; Barabach, S.; Statkiewicz-Barabach, G.; Sacha, K.; Müller, A.; Piskorski, J.; Barthel, P.; Schmidt, G. How to strengthen or weaken the HRV dependence on heart rate-Description of the method and its perspectives. Int. J. Cardiol. 2013, 168, 1660-1663. [CrossRef] [PubMed]

27. Thayer, J.F.; Lane, R.D. The role of vagal function in the risk for cardiovascular disease and mortality. Biol. Psychol. 2007, 74, 224-242. [CrossRef] [PubMed]

28. Cannon, J.G. Inflammatory Cytokines in Nonpathological States. News Physiol. Sci. 2000, 15, $298-303$. [CrossRef] 
29. Rohleder, N.; Aringer, M.; Boentert, M. Role of interleukin-6 in stress, sleep, and fatigue. Ann. N. Y. Acad. Sci. 2012, 1261, 88-96. [CrossRef]

30. Singh, S.; Torzewski, M. Fibroblasts and their pathological function in the fibrosis of aortic valve sclerosis and atherosclerosis. Biomolecules 2019, 9, 472. [CrossRef]

31. Didion, S.P. Cellular and oxidative mechanisms associated with interleukin-6 signaling in the vasculature. Int. J. Mol. Sci. 2017, 18, 2563. [CrossRef] [PubMed]

32. von Känel, R.; Nelesen, R.A.; Mills, P.J.; Ziegler, M.G.; Dimsdale, J.E. Relationship between heart rate variability, interleukin-6, and soluble tissue factor in healthy subjects. Brain Behav. Immun. 2008, 22, 461-468. [CrossRef] [PubMed]

33. Marsland, A.L.; Gianaros, P.J.; Prather, A.A.; Jennings, J.R.; Neumann, S.A.; Manuck, S.B. Stimulated production of proinflammatory cytokines covaries inversely with heart rate variability. Psychosom. Med. 2007, 69, 709-716. [CrossRef] [PubMed]

34. Zhang, H.; Park, Y.; Wu, J.; Chen, X.P.; Lee, S.; Yang, J.; Dellsperger, K.C.; Zhang, C. Role of TNF in vascular dysfunction. Clin. Sci. 2009, 116, 219-230. [CrossRef] [PubMed]

(C) 2019 by the authors. Licensee MDPI, Basel, Switzerland. This article is an open access article distributed under the terms and conditions of the Creative Commons Attribution (CC BY) license (http://creativecommons.org/licenses/by/4.0/). 